\title{
Comparison of Culture-Positive and -Negative Microbial Keratitis
}

(1) Semir Yarımada*, (1) Özlem Barut Selver*, (1) Melis Palamar*, (1) Sait Eğrilmez*, (1) Sabire Şöhret Aydemir**, (1) Süleyha Hilmioğlu Polat**, (1) Ayşe Yağc1*

*Ege University Faculty of Medicine, Department of Ophthalmology, İzmir, Turkey

**Ege University Faculty of Medicine, Department of Microbiology, İzmir, Turkey

\begin{abstract}
Objectives: To evaluate and compare the risk factors, presenting features, and outcomes of patients with culture-positive and culturenegative microbial keratitis (MK) who presented to a tertiary referral center.

Materials and Methods: We conducted a retrospective review of the medical records of 314 patients who were diagnosed with MK in our clinic between 2012 and 2019.

Results: Among 314 patients, 142 had positive cultures (45.2\%). The mean ages of the culture-positive and -negative patients at the time of diagnosis were $51.39 \pm 21.31$ (range, $14-90)$ years and $56.68 \pm 21.34$ (7-94) years, respectively $(\mathrm{p}=0.028)$. The mean best corrected visual acuity (BCVA) of the culture-positive and -negative patients were1.74 $\pm 1.25(0-3.1) \operatorname{LogMAR}$ and 1.91 $\pm 1.23(0-3.1) \log$ MAR prior to treatment and increased to $1.21 \pm 1.30(0-3.1) \operatorname{LogMAR}$ and $1.27 \pm 1.29(0-3.1) \operatorname{LogMAR}$ at last visit, respectively. There was no statistically significant difference between culture-positive and -negative patients' BCVA levels at presentation or last visit. Ninetytwo patients (64.7\%) were infected with bacteria and 50 patients (35.2\%) with fungi. The most common pathogen was Pseudomonas aeruginosa (18.3\%), followed by Streptococcus pneumoniae (11.2\%) and Fusarium spp. (11.2\%). Keratitis foci were either centrally or paracentrally located in 105 eyes (73.9\%) of culture-positive patients and 149 eyes (86.6\%) of culture-negative patients. Multiple foci were present mostly in culture-positive patients $(\mathrm{p}=0.001)$. There was no significant difference between the culture-positive and -negative groups in terms of hypopyon presence ( $\mathrm{p}=0.364)$. The proportion of contact lens $(\mathrm{CL})$ wearers was $33 \%$ ( $\mathrm{n}=47$ ) among culturepositive MK patients and $13.3 \%(\mathrm{n}=23)$ among culture-negative MK patients, respectively $(\mathrm{p}<0.001)$. Culture positivity was found to be significantly higher in keratitis associated with CL use $(\mathrm{p}=0.0001)$.

Conclusion: Microbiological analysis and culture evaluation are important steps in order to manage proper treatment in microbial keratitis. Prognosis mostly depends on the infectivity of the microbiological agent.

Keywords: Contact lens, culture, microbial keratitis
\end{abstract}

Address for Correspondence: Melis Palamar, Ege University Faculty of Medicine, Department of Ophthalmology, İzmir, Turkey E-mail: melispalamar@gmail.com ORCID-ID: orcid.org/0000-0002-2494-0131

Received: 25.12.2020 Accepted: 07.05.2021

Cite this article as: Yarımada S, Barut Selver Ö, Palamar M, Eğrilmez S, Aydemir SŞ, Hilmioğlu Polat S, Yağcı A. Comparison of Culture-Positive and -Negative Microbial Keratitis. Turk J Ophthalmol 2022;52:1-5

${ }^{\oplus}$ Copyright 2022 by Turkish Ophthalmological Association Turkish Journal of Ophthalmology, published by Galenos Publishing House. 


\section{Introduction}

Microbial keratitis is a severe disease that can result in corneal scarring, perforation, and finally blindness. Predisposing factors such as contact lens (CL) usage are usually present in the incident of the disease. Determining the incidence, microbial agent diversity, and predisposing factors of microbial keratitis are necessary for effective diagnosis, management, and prevention. ${ }^{1}$

The demographics and microbiological profile of the disease differ, and various reports have been published through the world. ${ }^{2,3}$ Shifting trends in the microbiological profile of keratitis have also been reported in some studies. ${ }^{4,5,6}$ Therefore, regular studies of the microbial profile are essential in order to determine local microorganisms and their antimicrobial sensitivities. ${ }^{7}$

The present study aimed to identify the features of culturepositive and culture-negative microbial keratitis in a tertiary referral center in İzmir, Turkey.

\section{Materials and Methods}

We performed a retrospective data analysis of patients who presented to our clinic between 2012 and 2019 with corneal ulcer findings suggestive of microbial keratitis (central and/or large ( $\geq 3 \mathrm{~mm}$ ) corneal infiltrates or corneal infiltrates extending to the mid to deep stroma, Figure 1) and underwent culture. The medical records of 314 patients were reviewed for demographic, clinical, and laboratory findings. Lesion characteristics including the location and number of keratitis foci were noted. Lesion location was defined as central if it invaded within $2 \mathrm{~mm}$ of fixation, peripheral if it involved a zone within $2 \mathrm{~mm}$ of the limbus, and paracentral if it was between the central and peripheral zone. Predisposing factors such as CL use, trauma, recurrent corneal erosion, corneal graft, and ocular or systemic disease, as well as the type of microorganism detected in culture were noted. The study adhered to the tenets of Declaration of Helsinki and was approved by the institutional ethics committee of our university.

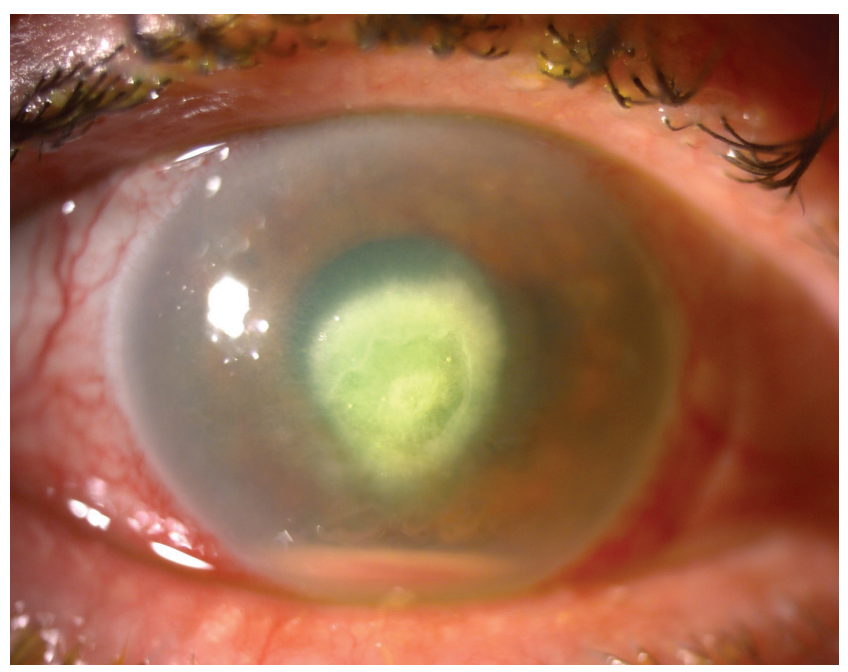

Figure 1. Central deep corneal infiltrates extending to the middle to deep stroma
Microbiological samples for Gram staining and cultures were obtained from the patients by a cornea specialist using a scalpel blade and cotton-tipped swab. If present, CLs and their solutions were also sent to the laboratory for microbiological investigation. Collected samples routinely underwent Gram staining and were inoculated on $5 \%$ sheep blood agar, EMB agar, chocolate agar, and Sabouraud agar for culturing. A culture result was noted as positive if microorganism growth was observed along the inoculation line in plates at 48 hours for bacteria or detected on Sabouraud agar after 6 weeks of incubation for fungi. Cultured microorganisms were identified using standard microbiological procedures. Antibiotic sensitivities were demonstrated based on antibiotic susceptibility testing standards of the Clinical Laboratory Standards Institute, using the VITEK 2 (Biomerioux, France) automated system. Patients were hospitalized and empirically initiated on topical fortified vancomycin (Vancotek $50 \mathrm{mg} / \mathrm{mL}$ vial, Kocak Farma, Turkey), ceftazidime (Iesetum $50 \mathrm{mg} / \mathrm{mL}$ vial, I.E. Ulagay, Turkey), and fluconazole (Fungan $0.2 \%$ vial, I.E. Ulagay, Turkey) drops hourly for the first 48 hours along with $1 \%$ cyclopentolate (Sikloplejin, Abdi Ibrahim, Turkey) 3 times a day and non-preserved artificial tear drops every 2 hours. Disruption of the tear film by the infection can lead to increased risk of ocular surface dryness and promote bacterial adhesion. Thus, to mimic tear film function and protect the ocular surface from dryness, preservative-free artificial tear solutions were used as a part of medical treatment. Moreover, artificial tears dilute the load of microbial and inflammatory agents in the tear film.

\section{Statistical Analysis}

According to microbiological results, treatment was modified to target the specific microorganism. Clinical improvement with this treatment was followed up until complete resolution of keratitis foci, seen as unstained stromal opacity with no signs of inflammation.

The statistical analysis was performed using SPSS software for Windows version 15.0 (SPSS Inc, Chicago, Illinois, USA) and Microsoft Office Excel (Microsoft, Redmond, Washington, USA). Statistical analyses were performed using frequency tables, paired t-test for within-group comparisons of best corrected visual acuity (BCVA) at presentation and last follow-up visit, unpaired $t$ test for comparisons of BCVA between the culturepositive and culture-negative groups, and chi-square test for qualitative data. A value of $\mathrm{p}<0.05$ was accepted as statistically significant.

\section{Results}

Among 314 patients, 142 had positive cultures (45.22\%). The mean ages of the culture-positive and -negative patients at the time of diagnosis were $51.39 \pm 21.31$ (range, 14-90) years and $56.68 \pm 21.34$ (range, 7-94) years, respectively $(\mathrm{p}=0.028)$. The male to female ratio in the culture-positive and culture-negative patients was 0.8 and 1.17 , respectively $(\mathrm{p}<0.001$, chi-square test). 
The mean time from symptom onset to diagnosis in the culture-positive and -negative patients was $27 \pm 24$ (range, 0-90) days and 13.2 \pm 16.8 (range, 1-90) days, respectively $(\mathrm{p}=0.014)$. The mean BCVAs of the culture-positive and -negative patients were $1.74 \pm 1.25$ (range, 0-3.1) LogMAR and 1.91 \pm 1.23 (range, 0-3.1) LogMAR prior to treatment and increased to $1.21 \pm 1.30$ (range, 0-3.1) LogMAR and 1.27 \pm 1.29 (range, 0-3.1) LogMAR at the end of the follow-up, respectively $(\mathrm{p}=0.0002 ; \mathrm{p}<0.001$, paired $t$ test). There was no statistically significant difference between culture-positive and -negative patients' BCVAs at presentation $(\mathrm{p}=0.316$, unpaired t test) or at last visit $(\mathrm{p}=0.716$, unpaired $t$ test) (Table 1 ).

In the culture-positive group, 92 patients (64.7\%) were infected with bacteria and 50 patients (35.2\%) with fungi. Among the cultured microorganisms, 30 different strains were identified (43.3\% gram-negative bacteria, $16.6 \%$ gram-positive bacteria, and $40 \%$ fungi). The most common pathogen was Pseudomonas aeruginosa (18.3\%), followed by Streptococcus pneumoniae (11.2\%) and Fusarium spp. (11.2\%). Culture results were positive for multiple species in 10 patients (7\%) (Table 2). No statistically significant difference was observed in BCVA after treatment in polymicrobial infections $(\mathrm{p}=0.068$, Wilcoxon nonparametric test). Evisceration surgery was performed to only one eye which had polymicrobial infection. According to culture results, fungal infections were associated with significantly worse BCVA. The mean BCVA of the fungal infection group was $2.15 \pm 1.14$ (range, 0.1-3.1) LogMAR, versus 1.61 \pm 1.26 (range, $0-3.1)$ LogMAR in bacterial infection group ( $\mathrm{p}=0.044$, unpaired t test).

Keratitis foci were either centrally or paracentrally located in 105 eyes $(73.9 \%)$ of the culture-positive patients and 149 eyes $(86.6 \%)$ of the culture-negative patients $(\mathrm{p}=0.001$, chi-square test). A single focus was present in $92(64.7 \%)$ culture-positive and in $161(93.6 \%)$ culture-negative patients ( $\mathrm{p}=0.0001$, chisquare test). Multiple foci were present in 50 eyes $(35.2 \%)$ of culture-positive and 11 eyes (6.4\%) of culture-negative patients ( $\mathrm{p}=0.0001$, chi-square test).

Table 1. The presenting features of the patients with microbial keratitis

\begin{tabular}{|c|c|c|c|}
\hline & $\begin{array}{l}\text { Patients with culture-positive } M K \\
\text { (mean } \pm \text { SD, range) }\end{array}$ & $\begin{array}{l}\text { Patients with culture-negative MK } \\
\text { (mean } \pm \text { SD, range) }\end{array}$ & p value \\
\hline Initial BCVA (LogMAR) & $\begin{array}{l}0.84 \pm 1.04 \\
(0-3.1)\end{array}$ & $\begin{array}{l}1.91 \pm 1.23 \\
(0-3.1)\end{array}$ & 0.649 \\
\hline Last BCVA (LogMAR) & $\begin{array}{l}0.28 \pm 0.46 \\
(0-3.1)\end{array}$ & $1.27 \pm 1.29 \quad(0-3.1)$ & 0.170 \\
\hline Mean duration of symptoms (days) & $\begin{array}{l}27 \pm 24 \\
(0-90)\end{array}$ & $\begin{array}{l}13.2 \pm 16.8 \\
(1-90)\end{array}$ & 0.014 \\
\hline $\begin{array}{l}\text { Number of keratitis foci, } \mathrm{n}(\%) \\
\text { Single focus } \\
\text { Multiple foci }\end{array}$ & $\begin{array}{l}92(64.7) \\
50(35.2)\end{array}$ & $\begin{array}{l}161(93.6) \\
11(6.4)\end{array}$ & 0.0001 \\
\hline $\begin{array}{l}\text { Location of keratitis foci, } \mathrm{n}(\%) \\
\text { Central/paracentral } \\
\text { Peripheral }\end{array}$ & $\begin{array}{l}105(73.9) \\
37(26.1)\end{array}$ & $\begin{array}{l}149(86.6) \\
23(13.3)\end{array}$ & 0.001 \\
\hline Hypopyon (n, \%) & $55(38.7)$ & $56(32.5)$ & 0.364 \\
\hline $\begin{array}{l}\text { Risk factors } \\
\text { Contact lens wear } \\
\text { Trauma with organic material } \\
\text { Corneal graft }\end{array}$ & $\begin{array}{l}47(33) \\
38(26.7) \\
19(13.3)\end{array}$ & $\begin{array}{l}23(13.3) \\
24(13.9) \\
15(8)\end{array}$ & $\begin{array}{l}0.0001 \\
0.007 \\
0.225\end{array}$ \\
\hline
\end{tabular}

\section{Table 2. Culture results of patients with microbial keratitis}

\begin{tabular}{|l|l|}
\hline Group and species & $\mathbf{n}(\%)$ \\
\hline Gram-negative bacteria & $43.3 \% *$ \\
Pseudomonas aeruginosa & $26(18.3)$ \\
\hline Gram-positive bacteria & $16.6 \% *$ \\
Streptococcus pneumoniae & $16(11.2)$ \\
Staphylococcus aureus & $6(4.2)$ \\
\hline Fungi & $38.7 \% *$ \\
Fusarium spp. & $16(11.2)$ \\
\hline *Percentage of the microorganism among all species isolated from culture $(\mathrm{n}=30)$ & \\
\hline
\end{tabular}


Repeated corneal scrapings were performed in 14 patients $(8.1 \%)$ due to the lack of clinical regression, but cultures of these samples were negative.

Hypopyon was present in 55 eyes $(38.7 \%)$ of culture-positive and in 56 eyes $(32.5 \%)$ of culture-negative patients $(p=0.364$, chi-square test).

The prevalence of ocular/systemic comorbidity in culturepositive and -negative patients was $28.1 \%(\mathrm{n}=40) / 30.2 \%(\mathrm{n}=43)$ and $33.1 \%(\mathrm{n}=57) / 37.2 \%(\mathrm{n}=64)$, respectively $(\mathrm{p}=0.251$ and $\mathrm{p}=0.133$, chi-square test). The most common accompanying systemic diseases in culture-positive and -negative patients were diabetes $(12 / 142,8.4 \%)$ and hypertension $(25 / 172,14.5 \%)$, respectively. The most common accompanying ocular disease in both culture-positive and -negative patients was glaucoma (8.1\% for both). Other associated ocular diseases were dry eye syndrome, bullous keratopathy, keratoconus, and exposure keratopathy.

Twenty-five $(14.5 \%)$ of the 172 culture-negative patients had a history of steroid use due to corneal transplantation $(\mathrm{n}=18)$, bullous keratopathy $(n=6)$, and marginal keratitis $(n=1)$.

The most common predisposing factor for culture-proven microbial keratitis was CL usage. The proportion of CL wearers was $33 \%(\mathrm{n}=47)$ among the culture-positive patients and $13.3 \%$ $(\mathrm{n}=23)$ among culture-negative patients. Culture positivity was found to be significantly higher in keratitis associated with CL use ( $p=0.0001$, chi-square test). All patients used frequent replacement soft CLs except one, who used a rigid gas-permeable CL. History of overnight wear and showering/swimming was reported by $50 \%$ and $58.9 \%$ of the CL wearers, respectively.

History of ocular trauma with organic material was present in $26.7 \%(n=38)$ of culture-positive patients and $13.9 \%(n=24)$ of culture-negative patients. Presence of corneal grafts was a predisposing factor in $13.3 \%(n=19)$ and $8 \%(n=15)$ of culturepositive and -negative patients, respectively.

The rate of antibiotic use before admission to our clinic was $36.7 \%$ in the culture-positive group and $45.9 \%$ in the culturenegative group ( $\mathrm{p}=0.097$, chi-square test). Positive clinical response to empiric antimicrobial treatment was observed in $59.1 \%$ and $86.6 \%$ of culture-positive and -negative patients, respectively $(\mathrm{p}<0.001)$.

Despite proper treatment according to antibiogram results, 47 patients $(33 \%)$ in the culture-positive group needed evisceration and penetrating keratoplasty surgery. In the culturenegative group, $18(10.4 \%)$ of the patients needed evisceration and penetrating keratoplasty surgery $(\mathrm{p}<0.001$, chi-square test). In order to limit infection and protect the eye, therapeutic keratoplasty was performed in $19.0 \%(\mathrm{n}=27)$ of the culturepositive and $8.7 \%(n=15)$ of culture-negative patients $(p=0.011$, chi-square test). Unfortunately, 8 patients in the culture-positive group and 3 patients in the culture-negative group underwent evisceration surgery.

\section{Discussion}

Microbial keratitis is one of the most common causes of corneal blindness worldwide. Although microbial agent characterization according to corneal scraping assessment is essential for effective treatment, clinicians need to start the antimicrobial regimen before culture and antibiogram results are available. The local microbial distribution pattern is one of the key factors in making this decision accurately. ${ }^{1}$ As geographical and climatic influences result in regional differences in the pattern of microbial isolates, local epidemiologic studies are important for this decision. ${ }^{2}$

Although microbial determination is essential, culture positivity rates reported in the literature range from 25.6 to $78 \%$. 1,2,4,5,6,7,8,9,10,11,12,13 Even though our clinic is a regional tertiary center and most patients were referrals who already received broad spectrum antimicrobial therapy before presentation, the positive culture rate for microbial keratitis was $45.2 \%$, consistent with the literature.

Microbial keratitis generally occurs in the presence of predisposing factors such as ocular trauma and CL wear. CL wear was reported to be the major risk factor for microbial keratitis in developed countries, with a prevalence of $34-50 \% .^{7,14,15}$ In developing countries, trauma remains the main risk factor, reported in $48-83 \%$ of cases. ${ }^{16,17,18}$ In the present study, CL wear $(33 \%)$ and trauma history $(26.7 \%)$ were the major risk factors.

As mentioned above, geographic and climatic influences result in regional variation in the pattern of microbial isolates, thus the microbiological profile of microbial keratitis differs between countries. Although gram-positive bacteria are more frequent in microbial keratitis according to the literature, ${ }^{1}$ Pseudomonas aeruginosa has been reported as the most common pathogen in several studies. ${ }^{14}$ In the present study, the most common microbial agent of culture-proven microbial keratitis was $P$. aeruginosa. In 2007, Yilmaz et al. ${ }^{19}$ reported the most common agents as gram-positive microorganisms among culture-proven microbial keratitis in the western part of Turkey, with a relatively high rate of $68.8 \%$. In their study, the most common predisposing factors were reported as trauma (26.6\%) and recent intraocular surgery $(17 \%)$. Only $3.2 \%$ of the patients were reported as CL wearers. The inconsistency between these two studies from the same region may be due to the substantial difference in predisposing factors and the increasing popularity of CLs in the last 13 years.

The proportion of fungal keratitis among microbial keratitis cases also varies by country due to topographic features and climatic effects. Fungal keratitis is much more prevalent in agricultural areas. ${ }^{14}$ The percentage of fungal keratitis was reported to be $5.3-40 \%$ in the literature. ${ }^{4,9,13,16}$ In our series, fungal keratitis accounted for $35.2 \%$ of the cases, and $75 \%$ of these patients had a history of ocular trauma with organic material. The high rate of fungal keratitis might be related to agriculture being common in Turkey.

Medical management was successful in $68.1 \%$ of the culturepositive patients and $89.6 \%$ of the culture-negative patients, which is consistent with the literature. ${ }^{20}$ We also observed that empirical treatment was more effective in the culture-negative group. Despite a higher rate of globe loss due to the infection in the culture-positive group, visual prognosis was similar in 
both groups. Similarly, Bhadange et al. ${ }^{20}$ reviewed culturepositive and -negative patients and reported that visual outcomes were comparable. In the culture-positive group, gram-negative microorganisms (e.g., $P$. aeruginosa), which have prominent destructive nature, were found to be the most common causative agents. The potential causative microorganisms in the culturenegative group were assumed to be gram-positive agents due to the ocular microbiota distribution. Thus, devastating complications were observed less frequently in the culturenegative group.

\section{Study Limitations}

The most important limitation of the present study was its retrospective nature. The most vital contribution was demonstrating the distribution of microbial agents in bacterial keratitis in a specific geographic region with a noteworthy amount of patient data.

\section{Conclusion}

The present study showed that CL wear was the major risk factor for microbial keratitis in the western part of Turkey, and $P$. aeruginosa was the most commonly isolated microbial agent. These results differ substantially from those of a previous study conducted in Turkey 13 years earlier and may demonstrate the current local microbial distribution pattern.

Ethics

Ethics Committee Approval: Ege University Medical Research Ethics Committee (approval number: 19-5.2T/68).

Informed Consent: Obtained.

Peer-review: Externally peer reviewed.

Authorship Contributions

Surgical and Medical Practices: M.P., Ö.B.S., A.Y., S.E., S.H.P., S.S..A., Concept: M.P., Design: Ö.B.S., A.Y., Data Collection or Processing: S.Y., Analysis or Interpretation: S.E., M.P., Literature Search: S.Y., M.P., Writing: Ö.B.S.

Conflict of Interest: No conflict of interest was declared by the authors.

Financial Disclosure: The authors declared that this study received no financial support.

\section{References}

1. Ng AL, To KK, Choi CC, Yuen LH, Yim SM, Chan KS, Lai JS, Wong IY. Predisposing Factors, Microbial Characteristics, and Clinical Outcome of Microbial Keratitis in a Tertiary Centre in Hong Kong: A 10-Year Experience. J Ophthalmol. 2015;2015:769436.
2. Lichtinger A, Yeung SN, Kim P, Amiran MD, Iovieno A, Elbaz U, Ku JY Wolff R, Rootman DS, Slomovic AR. Shifting trends in bacterial keratitis in Toronto: an 11-year review. Ophthalmology. 2012;119:1785-1790.

3. Sızmaz S, Bingöllü S, Erdem E, Kibar F, Koltaş S, Yağmur M, Ersöz R Polymicrobial Infection of the Cornea Due to Contact Lens Wear. Turk J Ophthalmol. 2016;46:83-86.

4. Green M, Apel A, Stapleton F. Risk factors and causative organisms in microbial keratitis. Cornea. 2008;27:22-27.

5. Ibrahim YW, Boase DL, Cree IA. Epidemiological characteristics, predisposing factors and microbiological profiles of infectious corneal ulcers: the Portsmouth corneal ulcer study. Br J Ophthalmol. 2009;93:1319-1324.

6. Aydemir S, Eğrilmez S, Masaroğulları M. Our Microbiological Analysis Results in Microbial Contact Lens Keratitis. Turk J Ophthalmol. 2010;40:349-353.

7. Bourcier T, Thomas F, Borderie V, Chaumeil C, Laroche L. Bacterial keratitis: predisposing factors, clinical and microbiological review of 300 cases. $\mathrm{Br} \mathrm{J}$ Ophthalmol. 2003;87:834-838.

8. Saeed A, D'Arcy F, Stack J, Collum LM, Power W, Beatty S. Risk factors, microbiological findings, and clinical outcomes in cases of microbial keratitis admitted to a tertiary referral center in ireland. Cornea. 2009;28:285-292.

9. Cariello AJ, Passos RM, Yu MC, Hofling-Lima AL. Microbial keratitis at a referral center in Brazil. Int Ophthalmol. 2011;31:197-204.

10. Shalchi Z, Gurbaxani A, Baker M, Nash J. Antibiotic resistance in microbial keratitis: ten-year experience of corneal scrapes in the United Kingdom. Ophthalmology. 2011;118:2161-2165.

11. Pandita A, Murphy C. Microbial keratitis in Waikato, New Zealand. Clin Exp Ophthalmol. 2011;39:393-397.

12. Hong J, Xu J, Hua J, Sun X. Bacterial keratitis in Shanghai. Ophthalmology. 2013;120:647.

13. Gopinathan U, Sharma S, Garg P, Rao GN. Review of epidemiological features, microbiological diagnosis and treatment outcome of microbial keratitis: experience of over a decade. Indian J Ophthalmol. 2009;57:273-279.

14. Lai TH, Jhanji V, Young AL. Microbial Keratitis Profile at a University Hospital in Hong Kong. Int Sch Res Notices. 2014;2014:689742.

15. Keay L, Edwards K, Naduvilath T, Taylor HR, Snibson GR, Forde K, Stapleton F. Microbial keratitis predisposing factors and morbidity. Ophthalmology. 2006;113:109-116.

16. Laspina F, Samudio M, Cibils D, Ta CN, Fariña N, Sanabria R, Klauss V, Miño de Kaspar H. Epidemiological characteristics of microbiological results on patients with infectious corneal ulcers: a 13-year survey in Paraguay. Graefes Arch Clin Exp Ophthalmol. 2004;242:204-209.

17. Srinivasan M, Gonzales CA, George C, Cevallos V, Mascarenhas JM, Asokan B, Wilkins J, Smolin G, Whitcher JP. Epidemiology and aetiological diagnosis of corneal ulceration in Madurai, south India. Br J Ophthalmol. 1997;81:965971.

18. Basak SK, Basak S, Mohanta A, Bhowmick A. Epidemiological and microbiological diagnosis of suppurative keratitis in Gangetic West Bengal, eastern India. Indian J Ophthalmol. 2005;53:17-22.

19. Yilmaz S, Ozturk I, Maden A. Microbial keratitis in West Anatolia, Turkey: a retrospective review. Int Ophthalmol. 2007;27:261-268.

20. Bhadange Y, Das S, Kasav MK, Sahu SK, Sharma S. Comparison of culturenegative and culture-positive microbial keratitis: cause of culture negativity, clinical features and final outcome. Br J Ophthalmol. 2015;99:1498-502. 